\title{
Evaluation of a malaria antibody enzyme immunoassay for use in blood screening
}

\author{
Jun Seo Oh, Jang Su Kim¹, Chang Hwan Lee', Deok Hwa Nam¹, Sun Hyung Kim¹, \\ Dae Won Park², Chang Kyu Lee1, Chae Seung Lim+, Gil Hong Park ${ }^{3}$ \\ Laboratory of Cellular Oncology ${ }^{1}$ Department of Laboratory Medicine, College of Medicine, Korea University Ansan Hospital, Gojan \\ 1-dong, Danwon gu, Ansan, Gyeonggi do 425-707, Republic of Korea 2Division of Infectious Disease, Department of Medicine \\ ${ }^{3}$ Department of Biochemistry, Korea University, Seoul, Republic of Korea
}

Transfusion-transmitted malaria is rare, but it may produce severe problem in the safety of blood transfusion due to the lack of reliable procedure to evaluate donors potentially exposed to malaria. Here, we evaluated a new enzyme-linked immunosorbent assay malaria antibody test (ELISA malaria antibody test, DiaMed, Switzerland) to detect antibodies to Plasmodium vivax (the indigenous malaria) in the blood samples in the Republic of Korea (ROK). Blood samples of four groups were obtained and analyzed; 100 samples from P.vivax infected patients, 35 from recovery patients, 366 from normal healthy individuals, and 325 from domestic travelers of non-endemic areas residents to risky areas of ROK. P.vivax antibody levels by ELISA were then compared to the results from microscopic examination and polymerase chain reaction (PCR) test. As a result, the ELISA malaria antibody test had a clinical sensitivity of $53.0 \%$ and a clinical specificity of $94.0 \%$ for P.vivax. Twenty out of 325 domestic travelers (6.2\%) were reactive and 28 cases $(8.6 \%)$ were doubtful. Of the reactive and doubtful cases, only two were confirmed as acute malaria by both microscopy and PCR test. Thus we found that the ELISA malaria antibody test was insufficiently sensitive for blood screening of P.vivax in ROK.

Key words: Plasmodium vivax - antibody test - transfusion - malaria antibody

Malaria can be transmitted by the transfusion of any blood component containing infected red blood cells (Mollison et al. 1997). The frequency of transfusion transmitted malaria varies from less than 0.2 in nonendemic countries to 50 or more cases per million in endemic countries (Mollison et al. 1997). Unfortunately, there is no reliable approved laboratory test to screen donated blood for malaria at present. The malaria antibody test was used for this purpose in some non-endemic countries (Seed et al. 2005). Consequently, exclusion of potentially infected donors is widely used to prevent transfusion transmitted malaria (Reesink 2005). Previous reports suggested that a malaria antibody test is effective in detecting malaria infection in travelers returning from overseas (Knappik et al. 2002) and in non-immune visitors to endemic areas after their departure (Jelinek et al. 1998, Knappik et al. 2002).

In the Republic of Korea (ROK), Plasmodium vivax is the only indigenous malaria, and was almost eradicated in the late 1970s. However, it has recently reemerged, especially North in the Delimited Militarized Zone (DMZ) areas, and cases have gradually increased to 4,140 in 2000 (KCDCP 2006). In the meantime, ten cases of transfusion transmitted malaria were reported in ROK (Cho et al. 2001b, Lee et al. 2001). Because a high sero-

Financial support: Seoul R\&BD (program 2007)

+ Corresponding author: malarim@korea.ac.kr

Jun Seo Oh and Jang Su Kim contributed equally to this work.

Received 5 September 2007

Accepted 14 January 2008 positive rate is expected in the residents of risky areas, the application of $P$. vivax antibody screening of blood donors in risky areas has been often questioned. Fortunately, the prevalence of malaria is very low in the ROK as a whole. Cases are largely restricted to sparsely populated areas near the North DMZ and are most abundant in the summer. The aim of this study is to evaluate a new enzyme-linked immunosorbent assay (ELISA) malaria antibody test for malaria detection in acute stages and in follow-up after treatment. We also evaluated the ELISA test for detection of malaria infection in visitors to endemic areas. Giemsa-stained blood smears were used as a standard method. In cases where results from ELISA malaria antibody test and microscopic examination differed, polymerase chain reaction (PCR) test was used to confirm the presence of parasite.

\section{SUBJECTS, MATERIALS AND METHODS}

Subjects - A total of 826 samples were collected with EDTA and no addictive tubes between April 2002 and August 2007 at Korea University Ansan Hospital, ROK. These blood samples comprised four groups: 100 from acute malaria patients (group 1- from P. vivax patients with parasitaemia) and 35 from post-treatment follow up (group 2 - from malaria patients followed up at least one month after treatment when no longer parasitaemic). Samples from normal controls $(n=366$, group 3$)$ were tested to determine assay specificity. These donors had no previous history of malaria and had not traveled to a malaria-endemic area in the previous three years. The last group of samples $(n=325)$ came from visitors to high-risk malaria areas within six months (group 4). Malaria risk areas in ROK are divided into three categories 
based on annual incidence per 100,000 residents: only one region is considered of high risk in 2005; six areas are considered of moderate risk and 12 are considered suspicious (KCDCP 2006). Donors in group 4 resided in malaria-free areas, had traveled to malaria risk areas, and were included regardless of the presence or absence of fever. Patient data was collected in face to face interviews and all subjects gave their written informed consent to participate in the study, which was approved by the Korea University Ansan Hospital Institutional Review Board. For malaria analysis, thick and thin blood films were prepared. Following Giemsa-staining of the blood films, the species and density of plasmodial parasites were determined by an expert in malaria diagnosis, using microscopic examination.

$P C R$ - Genomic DNA was extracted from frozen pellets using a Blood Genomic DNA Extraction kit (Bio-Solution, ROK) and stored at $-20^{\circ} \mathrm{C}$ or $-80^{\circ} \mathrm{C}$. Circumsporozoite protein (CSP) genes of $P$. vivax (Belem strain, M11926) were amplified by nested-PCR using the following oligonucleotide primers corresponding to nucleotides 266-1325: CSP-A1 (5'-GTCGGAATTC-ATGAAGAACT-TCATTCTC-3'), CSP-A3 (5'-GTAGATCTGTCCAAGGCCATAAATTTAA-3') and CSP-B1 (5'-GAGGACGCCGAAAATAATGGATG-3'). Internal primers were CSP-A2 (5'-TCTAGAGAAAATAAGCTGAAACAACCAGGA-3') and CSP-B2 (5'-AAGCTTCTAAACTTTATCTAGGTATTCTTTCA-3'), corresponding to base pairs 422-1,072. The first round of amplification was carried out using primer pair CSP-A1 or CSP-A3 and CSP-B1. The second round of nested-PCR was carried out in separate tubes each containing internal primer pair, CSP-A2 and CSP-B2. In both round of PCR, primers were used at a final concentration of 0.1 $\mu \mathrm{M}$ in $100 \mu \mathrm{l}$ reaction mixture $(10 \mathrm{mM}$ Tris- $\mathrm{HCl}, \mathrm{pH} 8.3$, $50 \mathrm{mMKCl}, 1.5 \mathrm{mMMgCl}, 0.2 \mathrm{mMeachdNTP}$ )containing $10 \mu \mathrm{l}$ of DNA or $5 \mu \mathrm{l}$ of template DNA in second round and 2.5 units of AmpliTaq polymerase (Perkin Elmer Co., Norwalk, CT, USA). Reaction mixtures were cycled 30 times: 1 min denaturation at $95^{\circ} \mathrm{C}, 1 \mathrm{~min}$ annealing at $53^{\circ} \mathrm{C}$, and 3 min extension at $72^{\circ} \mathrm{C}$ in a DNA thermal cycler (Perkin-Elmer Model 9600). The plasmids contain- ing P.vivax CSP gene and normal healthy control samples were used as positive and negative control of PCR test, respectively. Amplified products were size-fractionated by electrophoresis on $1.5 \%$ agarose gels containing ethidium bromide at a concentration of $0.5 \mathrm{mg} / \mathrm{ml}$.

ELISA malaria antibody test - The ELISA malaria antibody test (DiaMed, Switzerland) is based on binding of anti-Plasmodium antibodies present in a serum sample to antigens immobilized on 96-well plates. The antigens are a mixture of a total extract of cultured Plasmodium falciparum and recombinant $P$. vivax antigens merozoite surface protein (MSP)-1 and CSP. The test was performed as recommended by the manufacturer, as previously reported (Doderer et al. 2007). The cut-off value was calculated by multiplying the average optical density (OD) of the negative control wells by four (with a minimum value of $0.200)$. The antibody $(\mathrm{Ab})$ index of each determination is obtained by dividing the OD value of each sample by the cut-off value. A negative reaction corresponds to an $\mathrm{Ab}$ index of 0.8 or less, a positive reaction to an $\mathrm{Ab}$ index of 1.0 or more, and an equivocal result to an $\mathrm{Ab}$ index between 0.8 and 1.0. The test does not distinguish between IgG and IgM, or between antibodies to P. falciparum, $P$. vivax, Plasmodium ovale and Plasmodium malariae. The assay was carried out by an automatic ELISA processor (Bio-Rad CODA System, Bio-Rad, USA).

\section{RESULTS}

Clinical sensitivity in proven P. vivax malaria - The ELISA malaria antibody test gave positive results in $53.0 \%(53 / 100)$ of samples obtained from subjects with proven P. vivax malaria. Of the follow-up samples, $57.1 \%$ (20/35) tested positive. The PCR test, however, failed to detect parasite DNA in any of the follow-up cases, including those which tested positive (Table I).

Assay specificity in normal healthy controls - Of the 366 presumably non-exposed healthy controls, $22(6.0 \%)$ were reactive, but none had detectable parasitaemia by microscopic examination. Equivocally reactive samples were interpreted as negative in repeated test. Assay specificity was $94.0 \%$.

TABLE I

ELISA malaria antibody test and microscopy results for Plasmodium vivax infected patients, normal healthy controls and follow up cases

\begin{tabular}{|c|c|c|c|c|c|c|c|c|c|}
\hline & & $\begin{array}{r}I \\
\text { Micros } \\
(\mathrm{n}\end{array}$ & $\begin{array}{l}\text { vivax } \\
\text { opy positive } \\
=100)\end{array}$ & $\begin{array}{r}\text { Healt } \\
\text { Microsc } \\
(\mathrm{n}\end{array}$ & $\begin{array}{l}\text { ny control } \\
\text { opy negative } \\
=366)\end{array}$ & & $\begin{array}{r}\text { Follow } \\
\mathrm{M}\end{array}$ & $\begin{array}{l}\text { up cases } \\
\text { onth }\end{array}$ & \\
\hline & & $\mathrm{n}(\%)$ & $\begin{array}{c}\text { Mean } \\
\text { OD/cut off }\end{array}$ & $\mathrm{n}(\%)$ & $\begin{array}{c}\text { Mean } \\
\text { OD/cut off }\end{array}$ & $1-3(\%)$ & $3-6(\%)$ & $>6(\%)$ & Total $(\%)^{a}$ \\
\hline & Positive & $53(53)$ & $2.954 \pm 2.036$ & $22(6.0)^{a}$ & $1.698 \pm 0.750$ & $8(66.7)$ & $2(25.0)$ & $10(66.7)$ & $20(57.1)$ \\
\hline ELISA malaria & Equivocal $^{b}$ & $12(12)$ & $0.897 \pm 0.059$ & $18(4.9)^{a}$ & $0.911 \pm 0.315$ & $0(0)$ & $0(0)$ & $0(0)$ & $0(0)$ \\
\hline antibody test & Negative & $35(35)$ & $0.467 \pm 0.202$ & $326(89.1)$ & $0.349 \pm 0.315$ & $4(33.3)$ & $6(75.0)$ & $5(33.3)$ & $15(42.9)$ \\
\hline & Total & $100(100)$ & $1.837 \pm .907$ & $366(100)$ & $0.459 \pm 0.491$ & $12(100)$ & $8(100)$ & $15(100)$ & $35(100)$ \\
\hline
\end{tabular}

$a$ : absence of parasite was confirmed by PCR and microscopic examination; $b$ : equivocal region was interpreted as negative. OD: optical density. 
Clinical sensitivity in risky area visitor group - P. vivax was identified in 2 of 325 subjects by both microscopic examination and PCR test. ELISA test gave positive results for these two samples but was also positive for 18 other samples that were negative by both microscopy and PCR (Table II).

\section{TABLE II}

The seropositive rate by ELISA malaria antibody test in domestic travelers who returned from five regions in Korea

\begin{tabular}{lllcc}
\hline & & \multicolumn{2}{c}{ Microscopy } & \\
\cline { 3 - 4 } & & $\begin{array}{c}\text { positive } \\
\mathrm{n}(\%)\end{array}$ & $\begin{array}{c}\text { negative } \\
\mathrm{n}(\%)\end{array}$ & $\begin{array}{c}\text { Total } \\
\mathrm{n}(\%)\end{array}$ \\
\hline ELISA & Positive & $2(100)$ & $18(5.9)^{a}$ & $20(6.2)$ \\
malaria & Equivocal $^{b}$ & $0(0)$ & $28(9.2)^{a}$ & $28(8.6)$ \\
antibody & Negative $_{\text {test }}$ & $0(0)$ & $259(84.9)$ & $259(79.7)$ \\
& Total & $2(100)$ & $305(100)$ & $325(100)$ \\
\hline
\end{tabular}

$a$ : absence of parasite was confirmed by PCR and microscopic examination; $b$ : equivocal region was interpreted as negative.

\section{DISCUSSION}

Prevention program against the transfusion-transmitted malaria differs from nation to nation. The Council of Europe recommends that donors returning from malariaendemic countries may be accepted as blood donor if the result of a validated immunological test for antibodies to the malaria parasite, taken at least four months after last visit or since cessation of treatment and last symptom is negative (Council of Europe 2006). In non-endemic areas, the most widely-applied approach relies on identifying donors with a risk of malarial exposure by medical history-based questionnaires (Reesink 2005). After the resurgence of malaria in the ROK, ten cases of transfusion-mediated malaria were reported between 1997 and 2006 (Cho et al. 2001b, Lee et al. 2001), and malaria became a serious problem affecting blood donation policy. The ROK has donor deferral criteria of cellular product (red blood cell and platelet) restriction for periods of 12 or 36 months after domestic travel to, or residence in, malaria risk areas (KSBT 2007). Despite the strict adherence to donor exclusion guidelines, transfusion-transmitted malaria was reported to be unpreventable in the USA and UK (Purdy et al. 2004, Kitchen et al. 2005a, b).

At present there are no approved rapid tests for detecting an asymptomatic malaria infection that could be applied for large-scale screening in world blood centers. Standard microscopy takes too much time and requires educated personnel (Dodd 1998, Mungai et al. 2001). Recently, various kinds of rapid immunochromatographic test have been developed and evaluated for their sensitivities in various epidemiological settings (Palmer et al. 1998, Cho et al. 2001a). By their studies, the rapid diagnostic test (RDT), OptiMAL (DiaMed, Switzerland) and ICT (Amrad, Sydney, Australia), have shown to be effective, quick and easy method for detection of malaria
(Beadle et al. 1994). However, these tests have some limitations. In spite of excellent performance of RDT at high parasite densities, several studies have reported that the assay is not sufficiently sensitive at low parasite densities (Palmer et al. 1998, Cho et al. 2001a).

Immunofluorescence antibody test (IFAT) was regarded as the gold standard for malarial serology and until now has been used as the only validated method for detecting malaria antibodies in blood banks. In France, for example, IFAT has been used as a part of a targeted screening strategy combined with donor questionnare since 1983. IFAT is simple and satisfactorily sensitive, but also has disadvantages. It cannot be automated, which limits the number of sera that can be studied daily, readings can be influenced by trained status of technicians, and a fluorescent microscope is required. Additionally, the lack of standardization of IFAT reagents made it impossible to apply routinely in blood transfusion centers (Seed et al. 2005). Thus quick and enhanced tests are needed for use in blood banks to prevent spreading of malaria by transfusion.

Previous studies of malaria antibody assays have demonstrated sensitivity for $P$. falciparum in the range of $76-100 \%$ in acute samples, while sensitivity for $P$. vivax varies from $50-100 \%$ (Chiodini et al. 1997, Seed et al. 2005). Doderer et al. showed that the ELISA malaria antibody test kit (DiaMed, Switzerland) has a clinical sensitivity of $84.2 \%$ and a specificity of $99.6 \%$ and is less sensitive for $P$. vivax than P. falciparum (75\% vs. 95.5\%) (Doderer et al. 2007). Though this antibody test is three times as sensitive as IFAT (25\%) (Doderer et al. 2007), the number of $P$. vivax samples $(\mathrm{n}=24)$ was not enough to evaluate this kit in their study. Therefore, the aim of our study is to evaluate the accuracy of the ELISA malaria antibody test to detect $P$. vivax infections of possible blood donor. PCR and blood smears were used for comparison. In our study, sensitivity was not satisfactory in P. vivax infected cases from the ROK. For detection of $P$. vivax antibody, the test kit used recombinant $P$. vivax antigens (MSP-1 and CSP). The CSP and MSP-1 antigens of Korean strains are different from global isolates, which may have resulted in low sensitivity to $P$. vivax from the ROK (Lim et al. 2000, 2005). The appearance of malaria antibody in infected patients is affected by the interval after exposure (Jelinek et al. 1995). During the acute phase, circulating antibodies may not always be detectable. However, we consistently observed low sensitivity in follow up cases as well. Test specificity was an important point of the evaluation. The ELISA malaria antibody test showed relatively high specificity $(>94.0 \%)$ in normal healthy controls. The loss of donated blood due to false positives is predicted to be $5 \%$ of all tested.

The observed incidence of malarial antibodies in visitors from malarial-risk areas was $6.2 \%$ by ELISA. This result is higher than expected considering antigenic differences in Korean strains and the low annual prevalence in malaria risk areas compared to other tropical countries. Our study indicates that the malaria antibody has a great potential to identify malaria risk in blood. Although the ELISA malaria antibody test is a sensitive and relatively specific assay for $P$. falciparum, it is not ap- 
plicable to blood screening for $P$. vivax. Therefore, our results encourage efforts to improve malaria antibody detection methods for ROK-specific $P$. vivax in the field of blood screening for the prevention of transfusiontransmitted malaria.

\section{REFERENCES}

Beadle C, Long GW, Weiss WR, McElroy PD, Maret SM, Oloo AJ, Hoffman SL 1994. Diagnosis of malaria by detection of Plasmodium falciparum HRP-2 antigen with a rapid dipstick antigencapture assay. Lancet 343: 564-568.

Chiodini PL, Hartley S, Hewitt PE, Barbara JA, Lalloo K, Bligh J, Voller A 1997. Evaluation of a malaria antibody ELISA and its value in reducing potential wastage of red cell donations from blood donors exposed to malaria, with a note on a case of transfusion-transmitted malaria. Vox Sang 73: 143-148.

Cho D, Kim KH, Park SC, Kim YK, Lee KN, Lim CS 2001a. Evaluation of rapid immunocapture assays for diagnosis of Plasmodium vivax in Korea. Parasitol Res 87: 445-448.

Cho YH, Kwon SY, Seo DH, Kim SI 2001b. Transfusion transmitted malaria in Korea. Kor J Transf Med 12: 263-270.

Council of Europe 2006. Guide to the preparation, use and quality assurance of blood components, 12th ed., Council of Europe publishing, France, 42-43 pp.

Dodd RY 1998. Transmission of parasites by blood transfusion. Vox Sang 74 (Suppl. 2): 161-163.

Doderer C, Heschung A, Guntz P, Cazenave JP, Hansmann Y, Senegas A, Pfaff AW, Abdelrahman T, Candolfi E 2007. A new ELISA kit which uses a combination of Plasmodium falciparum extract and recombinant Plasmodium vivax antigens as an alternative to IFAT for detection of malaria antibodies. Malar J 6: 19.

Jelinek T, Bluml A, Loscher T, Nothdurft HD 1998. Assessing the incidence of infection with Plasmodium falciparum among international travelers. Am J Trop Med Hyg 59: 35-37.

Jelinek T, Nothdurft HD, Loscher T 1995. Evaluation of circumsporozoite antibody testing as a sero-epidemiological tool for the detection of Plasmodium falciparum infection in non-immune travelers. Trop Med Parasitol 46: 154-157.

KCDCP - Korea Center for Disease Control and Prevention 2006. Communicable Diseases Monthly Report 17: 1-11.
Kitchen A, Mijovic A, Hewitt PE 2005a. Transfusion-transmitted malaria: current donor selection guidelines are not sufficient. Vox Sang 88: 200-201.

Kitchen AD, Barbara JA, Hewitt PE 2005b. Documented cases of post-transfusion malaria occurring in England: a review in relation to current and proposed donor-selection guidelines. Vox Sang 89: 77-80.

Knappik M, Peyerl-Hoffmann G, Jelinek T 2002. Plasmodium falciparum: use of a NANP19 antibody-test for the detection of infection in non-immune travellers. Trop Med Int Health 7: 652-656.

KSBT - Korean Society of Blood Transfusion 2007. The recommendation of standard blood bank and blood center service, 2nd ed., Medrang Inforang, Seoul, $69 \mathrm{pp}$.

Lee YH, Lee HK, Choi KH, Hah JO, Lim SY 2001. Transfusioninduced malaria in a child after open heart surgery in Korea. $J$ Korean Med Sci 16: 789-791.

Lim CS, Kim SH, Kwon SI, Song JW, Song KJ, Lee KN 2000. Analysis of Plasmodium vivax merozoite surface protein-1 gene sequences from resurgent Korean isolates. Am J Trop Med Hyg 62: 261-265.

Lim CS, Tazi L, Ayala FJ 2005. Plasmodium vivax: recent world expansion and genetic identity to Plasmodium simium. Proc Natl Acad Sci USA 102: 15523-15528.

Mollison PL, Engelfriet CP, Contreras M 1997. Blood Transfusion in Clinical Medicine, 10th ed., Oxford - Blackwell Sciences, London, 509-557 pp.

Mungai M, Tegtmeier G, Chamberland M, Parise M 2001. Transfusion-transmitted malaria in the United States from 1963 through 1999. N Engl J Med 344: 1973-1978.

Palmer CJ, Lindo JF, Klaskala WI, Quesada JA, Kaminsky R, Baum MK, Ager AL 1998. Evaluation of the OptiMAL test for rapid diagnosis of Plasmodium vivax and Plasmodium falciparum malaria. J Clin Microbiol 36: 203-206.

Purdy E, Perry E, Gorlin J, Jensen K 2004. Transfusion-transmitted malaria: unpreventable by current donor exclusion guidelines? Transfusion 44: 464

Reesink HW 2005. European strategies against the parasite transfusion risk. Transfus Clin Biol 12: 1-4.

Seed CR, Kitchen A, Davis TM 2005. The current status and potential role of laboratory testing to prevent transfusion-transmitted malaria. Transfus Med Rev 19: 229-240. 